American Journal of Immunology 7 (1): 12-16, 2011

ISSN 1553-619X

(C) 2011 Science Publications

\title{
Immunologic Response to Hepatitis B Vaccine in Health Care Workers: A Screening Program and Evaluation of Some Host-Related Factors Role
}

\author{
${ }^{1}$ Mojtaba Varshochi and ${ }^{2}$ Roghayyeh Mahmodian \\ ${ }^{1}$ Infectious Diseases and Tropical Medicine Research Center, \\ ${ }^{2}$ Department of Infection Control Nurse, Cardiovascular Research Center, \\ Faculty of medicine, Tabriz University of Medical Sciences, Tabriz, Iran
}

\begin{abstract}
Problem statement: To evaluation the immunologic response to hepatitis B vaccine in health care's workers and effects of host-related factors? Approach: In a cross sectional descriptive analytic study carried out on the medical staff of Tabriz Shahid Madani Hospital in 2009-2010, we evaluated the immunologic response of the staff to vaccination against Hepatitis $\mathrm{B}$ and factors affecting it. Results: The mean antibody titer in the studied medical staff was $366.76 \pm 169.714 \mathrm{IU} \mathrm{L}^{-1}$. $2.05 \%$ were in "no response" group, $1.46 \%$ in "Low response" group and $96.49 \%$ in "Good response" group. Conclusion: Immunological response in the smoking staff was significantly less $(\mathrm{p}<0.001)$ but no significant difference was observed in the response between genders $(p=0.127)$ and no case of hyperlipidemia was reported. There was a significant reverse linear relation between age and antibody titer in the studied staff ( $\mathrm{p}=0.003, \mathrm{R}=0.162)$ but no significant linear relation was observed between weight, height and BMI and antibody titer.
\end{abstract}

Key words: Hepatitis B vaccines, occupational diseases, prevention and control, linear relation, antibody titer, factors affecting, immunologic response, analytic study, host-related factors

\section{INTRODUCTION}

Hepatitis B Virus (HBV) infection represents a major health problem, with 2 billion people infected worldwide and more than 400 million chronic carriers of $\mathrm{HBV}$. Globally it causes about 1.2 million deaths per year due to various complications including chronic hepatitis, cirrhosis and liver cancer (Hou et al., 2005; Lavanchy, 2004; Michielsen et al., 2005; Seeger and Mason, 2000).

Hepatitis B comprises one of the major health problems worldwide (Perez et al., 1998). Infection with hepatitis B virus has become a vaccine-preventable disease (Leroux-Roels et al., 2001). Vaccination against Hepatitis B Virus infection (HBV) is safe and effective; however, vaccine-induced antibody level wanes over time (Hennig et al., 2008). Health Care Workers (HCW) are a group at risk for Hepatitis B Virus (HBV) infection (Oliveira et al., 1995). Protection against hepatitis $B$ virus infection by vaccination is considered to be an important preventive measure for health care workers (Rachiotis et al., 2005). Hepatitis B vaccination is recommended for all Health Care
Workers (HCW) at risk of exposure to infectious body fluids (Williams et al., 2001). Health care workers' immunization against hepatitis $\mathrm{B}$ is an essential measure to avoid occupational transmission of hepatitis $\mathrm{B}$ virus at primary health care centers (Garcia and Facchini, 2008). The overall serum protection rate was 97.5 and $46.7 \%$ of the sample responded showing titers of over $100 \mathrm{mIU} \mathrm{ML}^{-1}$ (Perez et al., 1998). Hepatitis B vaccine is a vaccine developed for the prevention of hepatitis B virus infection. The vaccine contains one of the viral envelope proteins, Hepatitis B surface antigen (HBsAg). It is produced by yeast cells, into which the genetic code for HBsAg has been inserted. A course of three vaccine injections are given with the second injection at least one month after the first dose and the third injection given six months after the first dose. Afterward an immune system antibody to $\mathrm{HBsAg}$ is established in the bloodstream. The protective antibody is known as anti-HBsAg. This antibody and immune system memory then provide immunity to hepatitis B infection. The first vaccine became available in 1981 (Hou et al., 2005). The aim of this study was evaluation

Corresponding Author: Mojtaba Varshochi, Infectious Diseases and Tropical Medicine Research Center,

Tabriz University of Medical Sciences, Tabriz, Iran Tel: +98-9143135846 
the immunologic response to hepatitis $\mathrm{B}$ vaccine in health care workers and effects of some host-related factors.

\section{MATERIALS AND METHODS}

In a cross sectional descriptive analytic study carried out on the medical staff of Tabriz Shahid Madani Hospital in 2009-2010, we evaluated the immunologic response of the staff to vaccination against Hepatitis B and factors affecting it.

Medical staff is routinely vaccinated against hepatitis B and therefore antibody titration is essential to insure appropriate immunity.

The studied medical staffs are vaccinated by hepatitis B vaccine with fallowing properties (entitled EUVAX B, met the WHO requirements, made in Korea, LG life sciences company) for three doses $(0,1$ and 6 months) and antibody was titrated three months after vaccination. All utilized vaccines were from one brand and all tests were performed in one laboratory.

ELISA test was used to evaluate the samples used kit in this study was the Anti-HBs kit, made by ROCHE Company entitled "COBAS". Methods of this kit was ELISA, in which ELISA micro plates in this method ELISA micro plates are covered by antigen $S$ so that after adding serum containing antibodies against antigen $\mathrm{S}$, antigens would bind with antibodies. In the next step, antigen $\mathrm{S}$ conjugated with peroxidase enzyme is added which attaches to the part of the antibodies not bound to antigens. Later, adding chromogene and substrate dies the solution whose color can be read by ELISA reader.

After performing tests and reading the plates by ELISA reader, standard curves were provided using standard samples. Later using these curves, the concentration of antibodies in the tested sample were calculated. Based on the instructions of the kit manufacturer, antibody level less than 10 units per mL was considered negative and amounts higher as positive.

\section{RESULTS}

This study was carried out on 341 people from the medical staff and HBsAg titers were measured after three dose vaccination ( 0,1 and 6 months), the following results were obtained.

126 people (37\%) from the studied staff were male and 215 people $(63 \%)$ female. Demographic data of the studied medical staff are presented in Table 1.
Table 1: Demographic factors of health care workers

\begin{tabular}{llll}
\hline & Sex & & \\
& Male & Female & P_value \\
\hline Age (year) & $34 \pm 9$ & $30 \pm 6$ & $<0.001$ \\
Length (m) & $1.71 \pm 0.07$ & $1.60 \pm 0.06$ & $<0.001$ \\
Weight (Kg) & $74 \pm 12$ & $62 \pm 11$ & $<0.001$ \\
BMI & $25.55 \pm 4.02$ & $24.13 \pm 3.86$ & 0.002 \\
Smoker & 15 & 1 & $<0.001$ \\
HLP & 30 & 10 & $<0.001$ \\
\hline
\end{tabular}

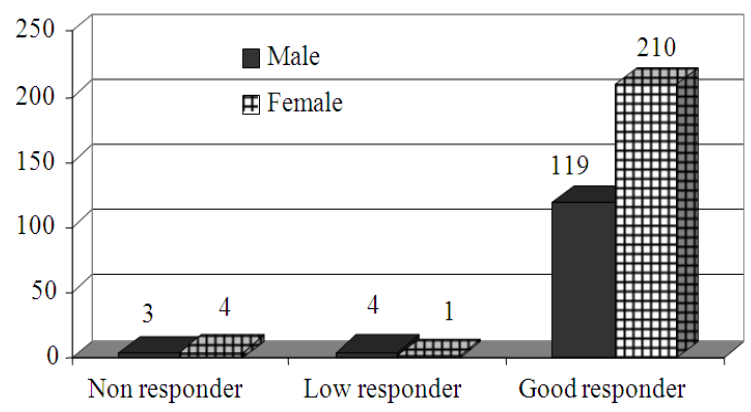

Fig. 1: Repose to vaccination in studied health workers between two sexes $(P=0.127)$

The mean antibody titer in the studied medical staff was $366.76 \pm 169.714 \mathrm{IU} \mathrm{L}^{-1}$ in the range of 1-1000 IU $\mathrm{L}^{-1}$ and median of $382 \mathrm{IU} \mathrm{L}^{-1}$.

Antibody titer of the studied staff according to gender, smoking and hyperlipidemia are presented in Table 2.

Dividing the antibody titer into three groups of "no response" (Titer<10 IU L-1), "Low response" (Titer10-100 IU L-1) and "Good response" (Titer $>100$ IU L-1) revealed that from 341 studied staff, 7 people $(2.05 \%)$ were in "no response" group, 5 people $(1.46 \%)$ in "Low response" group and 329 people $(96.49 \%)$ in "Good response" group.

Response of the staff according to gender, smoking and hyperlipidemia are presented in Fig. 1-3 which shows that response in the smoking staff was significantly less $(\mathrm{p}<0.001)$ but no significant difference was observed in the response between genders $(p=0.127)$ and no case of hyperlipidemia was reported.

There was a significant reverse linear relation between age and antibody titer in the studied staff and antibody titer decreased significantly as age increased $(\mathrm{p}=0.003, \mathrm{R}=-0.162)$ but no significant linear relation was observed between weight, height and BMI and antibody titer. 
Am. J. Immunol., 7 (1): 12-16, 2011

Table 2: Antibody titer of health care workers at the base of sex, smoking and hyperlipidemia

\begin{tabular}{|c|c|c|c|c|c|c|c|c|c|}
\hline & & \multirow[b]{2}{*}{ Mean \pm Std } & \multirow[b]{2}{*}{ Median } & \multicolumn{5}{|c|}{ Titer antibody (IU/L) } & \multirow[b]{2}{*}{ P_Value } \\
\hline & & & & Percentile 05 & Percentile 25 & Percentile 75 & Percentile 95 & Percentile 99 & \\
\hline \multirow[t]{2}{*}{$\overline{S e x}$} & male & $385 \pm 176$ & 419 & 50 & 270 & 491 & 607 & 995 & 0.130 \\
\hline & Female & $356 \pm 165$ & 370 & 100 & 220 & 485 & 602 & 734 & \\
\hline \multirow[t]{2}{*}{ Smoking } & No & $368 \pm 168$ & 382 & 100 & 236 & 485 & 605 & 787 & 0.541 \\
\hline & Yes & $341 \pm 207$ & 398 & 2 & 95 & 496 & - & - & \\
\hline \multirow[t]{2}{*}{ Hyperlipidemia } & Yes & $382 \pm 177$ & 414 & 12 & 263 & 480 & 605 & - & 0.555 \\
\hline & No & $365 \pm 169$ & 380 & 100 & 230 & 488 & 606 & 749 & \\
\hline
\end{tabular}

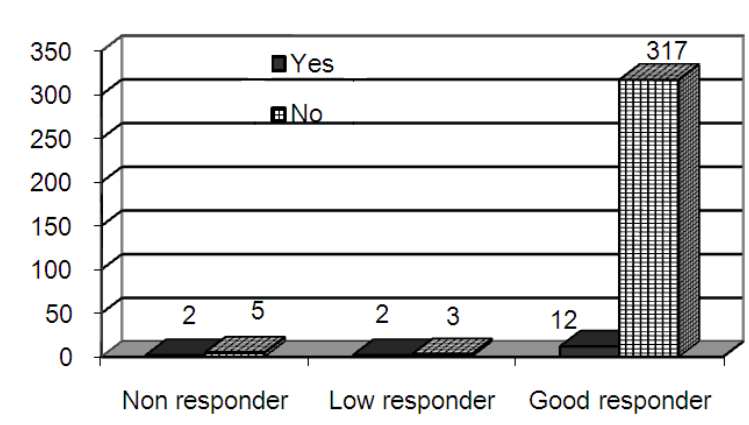

Fig. 2: Repose to Vaccination in studied health workers in smokers and nonsmokers $(\mathrm{P}<0.001)$

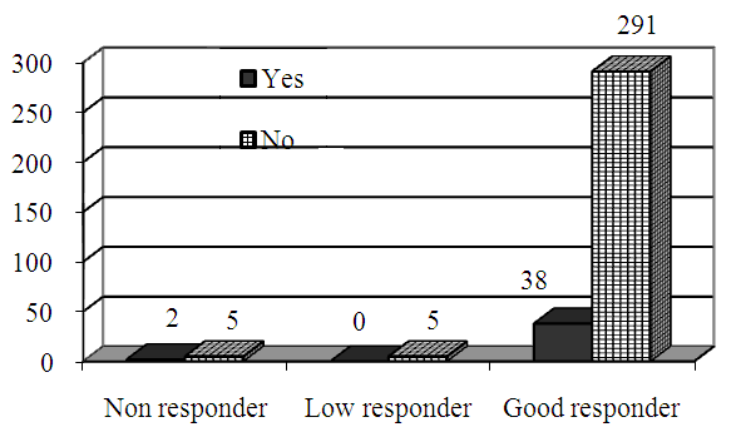

Fig. 3: Repose to Vaccination in studied health workers by $\operatorname{HLP}(\mathrm{P}=0.571)$

\section{DISCUSSION}

Hepatitis B is one of the important vocational diseases threatening medical staff. The main prevention method is vaccination against hepatitis B and maintaining appropriate immunity. High immunity level of the staff working in hospitals and other health centers can reduce hepatitis B infection among personnel. In this study we evaluated vaccination and immunity status in the personnel working in Shahid Madani Hospital.

Hepatitis B is one of the threatening infectious diseases in the staff of the medical centers. Infection risk of the hepatitis $B$ in the medical staff is four times more compared to the normal adult population and the people who are not active in the field (Lavanchy, 2004).

Immunity level of the medical staff in our country has been reported to be $50-90 \%$ in the different studies carried out (Zali et al., 1996). In a study carried out by Jack et al. (1999) in Gambia within seven years it was concluded that children having antibody titers higher than 10 units in $\mathrm{mL}$ were immune against hepatitis $\mathrm{B}$ at least within the study period (seven years), whereas children having lower levels of antibody (less than 10 units in $\mathrm{mL}$ ) were infected by hepatitis $\mathrm{B}$ in the following years (Jack et al., 1999).

Geometric mean titers of anti-HBs after vaccination were also higher in the females than in the males $\left(257 \pm 19.7\right.$ Vs. $29 \pm 1.88 \mathrm{Miu} \mathrm{mL}^{-1}, \mathrm{P}=$ $0.01,1802 \pm 35.2$ vs. $306 \pm 13.6 \mathrm{mIU} \mathrm{mL}^{-1}, \mathrm{P}<$ or $=$ $0.05,6465 \pm 72$ vs. $\left.2142 \pm 73.6 \mathrm{mIU} \mathrm{mL}^{-1}, \mathrm{P}<0.05\right)$ (Thakur et al., 2010).

In our study antibody titers in the studied males and females were $385 \pm 176 \mathrm{IU} \mathrm{L}^{-1}$ and $385 \pm 176 \mathrm{IU}$ $\mathrm{L}^{-1}$ respectively $(\mathrm{p}=0.130)$.

In a study carried out in the US, it was identified that hepatitis B vaccination was effective in $72 \%$ of nurses and $71 \%$ of the physicians (Beltrami et al., 2000).

In 1991 in England almost 94\% and in 1990 in another study $3 / 4$ of the people $(75 \%)$ and half of the residents were vaccinated whereas in Berlin only were $74 \%$ of dentists and $63 \%$ of their residents were vaccinated (Martins and Barre, 2003).

The overall serum protection rate was 97.5 and $46.7 \%$ of the sample responded showing titers of over $100 \mathrm{mU} \mathrm{mL}^{-1}$.

Anti-HBsAb titers were $>100 \mathrm{mLU} \mathrm{mL}^{-1}$ in 211 subjects $(62.2 \%), 10-100 \mathrm{mLU} / \mathrm{mL}$ in $85(25.1 \%)$ and $<10 \mathrm{mLU} \mathrm{mL}^{-1}$ in $43(12.7 \%)$ persons (Saberifiroozi et al., 2006). The overall antibody response rate was $95 \%$ (Cockcroft et al., 1990).

In our study, Anti-HBsAb titers were $>100 \mathrm{mLU}$ $\mathrm{mL}^{-1}$ in 329 persons $(96.49 \%), 10-100 \mathrm{mLU} \mathrm{mL}^{-1}$ in 5 $(1.46 \%)$ and $<10 \mathrm{mLU} \mathrm{mL}^{-1}$ in $7(2.05 \%)$ persons.

Compared to the above-mentioned studies, our study showed a better coverage. 
Previous studies have shown that $5-15 \%$ of healthy people do not show a protective antibody response following hepatitis B vaccination.

9.5\% were non-responders (Perera et al., 2002). Duration of vaccination, sex and body mass index was not significantly associated with anti-HBs levels (Perera et al., 2002).

The responders were significantly younger than the non-responders and had significantly lower values of body mass index (wt/ht $\left.{ }^{2}\right)$ (Cockcroft et al., 1990).

In our study only 12 people from the studied sample had antibody titers less than 100 after vaccination.

Smoking and alcoholism were significantly correlated with unsatisfactory response (Thakur et al., 2010).

Female sex, intramuscular vaccination, young age and being a non-smoker were associated with a higher response rate and a higher geometric mean anti-HBs titer than male sex, intradermal vaccination, old age and being a smoker (Struve et al., 1992).

Stratifying by vaccine brand demonstrated that age $(\mathrm{P}=0.01)$, body mass index $(\mathrm{P}<0.01)$ and smoking status $(\mathrm{P}<0.01)$ were associated with lacking anti-HBs only for Recombivax HB recipients; and gender $(\mathrm{P}=$ $0.03)$ was associated with lacking anti-HBs only for Engerix-B recipients (Wood et al., 1993).

In our study there was a significant reverse linear relation between antibody titer and age of the patients $(\mathrm{R}=-0.162$ and $\mathrm{P}=0.003)$ whereas no significant difference was observed regarding weight $(\mathrm{P}=0.764)$, height $(\mathrm{P}=0.321)$ and $\mathrm{BMI}(\mathrm{P}=0.407)$. Also no significant relation was observed in antibody titers between smoking, non-smoking and hyperlipidemic people $(\mathrm{P}=0.555)$.

In our study also antibody titer significantly decreased as the age of the patients increased. "No response" was observed in people below 25 years 0 , $0.3 \%$ in the age range of $25-34,0.9 \%$ in the age range of 35-49 and $0.9 \%$ in the age range of over 50 .

Testing of blood for anti-HBs one month after vaccination is recommended to recognize nonresponders as a booster dose will be beneficial in the majority of them (Perera et al., 2002).

We recommend (a) post vaccination testing within 1-3 months to document immunity, (b) periodic antiHBs monitoring and (c) booster vaccination to maintain protective titer levels.

\section{CONCLUSION}

From 341 studied people, seven (2.05\%) showed no response to vaccination, five $(1.46 \%)$ low response and 329 (96.49\%) good response. In our study there was a significant reverse linear relation between antibody title and age whereas no significant relation was observed with weight, height and BMI. Also there was no significant relation regarding antibody titer with smoking, non-smoking and hyperlipidemic.

\section{REFERENCES}

Beltrami, E.M., I.T. Williams, C.N. Shapiro and M.E. Chamberland, 2000. Risk and management of blood-borne infections in health care workers. Clin. Microbiaol Rev., 13: 385-407. DOI: 10.1128/CMR.13.3.385-407.2000 PMID: 10885983

Cockcroft, A., P. Soper, C. Insall, Y. Kennard and S. Chapman et al., 1990. Antibody response after hepatitis B immunisation in a group of health care workers. Br. J. Ind. Med., 47: 199-202. PMID: 2139341

Garcia, L.P. and L.A. Facchini, 2008. Hepatitis B vaccination among primary health care workers. Cad. Saude Publica., 24: 1130-1140. PMID: 18461242

Hennig, B.J., K. Fielding, J. Broxholme, M. Diatta and M. Mendy et al., 2008. Host genetic factors and vaccine-induced immunity to hepatitis B virus infection. PLoS One, 3: e1898-e1898. PMID: 18365030

Hou, J., Z. Liu and F. Gu, 2005. Epidemiology and prevention of hepatitis B virus infection. Int. J. Med. Sci., 2: 50-57. PMID: 15968340

Jack, A.D., A.J. Hall, N. Maine, M. Mendy and H.C. Whittle, 1999. What level of hepatitis B antibody is protective? J. Infect. Dis., 179: 489-492. DOI: 10.1086/314578 PMID: 9878036

Lavanchy, D., 2004. Hepatitis B virus epidemiology, disease burden, treatment and current and emerging prevention and control measures. J. Viral Hepat., 11: 97-107. DOI: $10.1046 /$ j.13652893.2003.00487.x PMID: 14996343

Leroux-Roels, G., T. Cao, A.D. Knibber, P. Meuleman and A. Roobrouck et al., 2001. Prevention of hepatitis B infections: vaccination and its limitations. Acta Clin. Belg., 56: 209-19. PMID: 11603250

Martins, A.M. and S.M. Barre, 2003. Hepatitis B vaccination among dentists. Rev. Saude. Publica., 37: 333-338. PMID: 12792684

Michielsen, P.P., S.M. Francque and J.L. Van Dongen, 2005. Viral hepatitis and hepatocellular carcinoma. World J. Surg. Oncol., 3: 27-27. DOI: 10.1186/1477-7819-3-27 PMID: 15907199 
Oliveira, P.M.C., A.E. Silva, V.L. Kemp, Y. Juliano and M.L. Ferraz, 1995. Comparison of three different schedules of vaccination against hepatitis $B$ in health care workers. Vaccine, 13: 791-794. DOI: 10.1016/0264-410X(94)00064-T

Perez, J.A.M., B.J.E. Santamaria, G.M, Luengo, C.L. Moreno and S.C. Alcaizar et al., 1998. Coverage and immune response to hepatitis B vaccine in adolescents of the Guadalajara province. Rev. Esp. Salud. Publica., 72: 119-126. PMID: 9643067

Perera, J., B. Perera and S. Gamage, 2002. Seroconversion after hepatitis B vaccination in healthy young adults and the effect of a booster dose. Ceylon Med. J., 47: 6-8. PMID: 12001615

Rachiotis, G., C. Goritsas, V. Alikakou, A. Ferti and A. Roumeliotou, 2005. Vaccination against hepatitis B virus in workers of a general hospital in Athens. Med. Lav., 96: 80-86. PMID: 15847111

Saberifiroozi, M., S. Gholamzadeh and A.R. Serati, 2006. The long-term immunity among health care workers vaccinated against hepatitis B virus in a large referral hospital in southern Iran. Arch. Iran Med., 9: 204-207. PMID: 16859051

Seeger, C. and W.S. Mason, 2000. Hepatitis B virus biology. Microbiol. Mol. Biol. Rev., 64: 51-68. DOI: 10.1128/MMBR.64.1.51-68.2000 PMID: 10704474
Struve, J., B. Aronsson, B. Frenning, F. Granath and M.V. Sydow et al., 1992. Intramuscular versus intradermal administration of a recombinant hepatitis B vaccine: A comparison of response rates and analysis of factors influencing the antibody response. Scand. J. Infect. Dis., 24: 423429. DOI: $10.3109 / 00365549209052627$ PMID: 1411307

Thakur, V., N.T. Pati, R.C. Gupta and S.K. Sarin, 2010. Efficacy of Shanvac-B recombinant DNA hepatitis $B$ vaccine in health care workers of Northern India. Hepatobiliary Pancreat. Dis. Int., 9: 393-397. PMID: 20688603

Williams, J.L., C.J. Christensen, B.J. McMahon, L.R. Bulkow and H.H. Cagle et al., 2001. Evaluation of the response to a booster dose of hepatitis B vaccine in previously immunized healthcare workers. Vaccine, 19: 4081-4085. DOI: 10.1016/S0264-410X(01)00112-8

Wood, R.C., K.L. MacDonald, K.E. White, C.W. Hedberg and M. Hanson et al., 1993. Risk factors for lack of detectable antibody following hepatitis $B$ vaccination of Minnesota health care workers. JAMA., 270: 2935-2939. DOI: 10.1001/jama.1993.03510240047030 PMID: 8254853

Zali, M.R., K. Mohammad, A. Farhadi, M.R. Masjedi and A. Zargar et al., 1996. Epidemiology of hepatitis B in the Islamic Republic of Iran. East Meditter. Health J., 2: 290-298. 